\title{
Idiopathic hypertrophic obstructive cardiomyopathy causing severe right ventricular outflow tract obstruction in infancy
}

\author{
P. A. Barr, J. M. Celermajer, J. D. Bowdler, and T. B. Cartmill \\ From the Adolph Basser Institute of Cardiology, Royal Alexandra Hospital for Children, Sydney, Australia
}

Two infants with idiopathic hypertrophic obstructive cardiomyopathy, presenting as severe right ventricular outflow obstruction, are described. The nonspecific clinical features and an unexpected angiocardiographic appearance made correct diagnosis difficult. One of the infants was mistakenly diagnosed as having severe pulmonary valve stenosis. It is suggested that angiocardiography may be diagnostic. Attempted surgical correction was unsuccessful in the infants reported. Infants with idiopathic hypertrophic obstructive cardiomyopathy should be managed, at least initially, with beta-adrenergic receptor blocking agents.

Idiopathic hypertrophic obstructive cardiomyopathy has received considerable attention since the initial pathological description by Teare (1958). The clinical features and natural history of patients presenting in the second and third decades of life have been reviewed extensively (Cohen et al., 1964; Braunwald et al., 1964; Swan et al., 1971). In infancy it is rare (Neufeld, Ongley, and Edwards, I960; Daoud, Gallaher, and Kaplan, I961; Moes, Peckham, and Keith, 1964; Lundquist et al., 1965;

Received 30 May 1973.
Rudhe, Zetterqvist, and Wallgren, I966; Shand, Sell, and Oates, 1971). Idiopathic hypertrophic obstructive cardiomyopathy presenting as right ventricular outflow obstruction in infancy, to our knowledge, has been reported only twice (Neufeld et al., 1960; Lundquist et al., 1965).

This report describes 2 infants with severe right ventricular outflow obstruction due to idiopathic hypertrophic obstructive cardiomyopathy. The difficulty encountered in diagnosis and management and the important angiocardiographic features are discussed.

TABLE Hypertrophic obstructive cardiomyopathy: cardiac catheterization

\begin{tabular}{|c|c|c|c|c|c|c|c|c|c|c|c|c|}
\hline \multirow{2}{*}{ Case } & \multicolumn{6}{|c|}{ Pressure $(\mathrm{mm} H g)$} & \multicolumn{6}{|c|}{ Oxygen saturation (\%) } \\
\hline & $\begin{array}{l}\text { Right } \\
\text { atrium }\end{array}$ & $\begin{array}{l}\text { Right } \\
\text { ventricle }\end{array}$ & $\begin{array}{l}\text { Pulmonary } \\
\text { vein } \\
\text { wedge }\end{array}$ & $\begin{array}{l}\text { Left } \\
\text { atrium }\end{array}$ & $\begin{array}{l}\text { Left } \\
\text { ventricle }\end{array}$ & $\begin{array}{l}\text { Systemic } \\
\text { artery } \\
\text { (cuff) }\end{array}$ & $\begin{array}{l}\text { Superior } \\
\text { vena } \\
\text { cava }\end{array}$ & $\begin{array}{l}\text { Right } \\
\text { atrium }\end{array}$ & $\begin{array}{l}\text { Right } \\
\text { ventricle }\end{array}$ & $\begin{array}{l}\text { Pulmonary } \\
\text { vein }\end{array}$ & $\begin{array}{l}\text { Left } \\
\text { atrium }\end{array}$ & $\begin{array}{l}\text { Left } \\
\text { ventricle }\end{array}$ \\
\hline $\mathbf{I}$ & $\begin{array}{l}a=22 \\
\overline{7}\end{array}$ & 155/0-10 & $\begin{array}{l}27 / 17 \\
\overline{19}\end{array}$ & $\begin{array}{l}a=30 \\
v=10 \\
\overline{1 O}\end{array}$ & $165 / 0-12$ & $90 /-$ & 48 & $5 I$ & 44 & 100 & 93 & 95 \\
\hline 2 & $\begin{array}{l}a=15 \\
\overline{3}\end{array}$ & $150 / 0-14$ & $\begin{array}{l}20 / 15 \\
\overline{15}\end{array}$ & $\begin{array}{l}a=13 \\
v=13 \\
\overline{5}\end{array}$ & - & - & 53 & 52 & 48 & 94 & 88 & - \\
\hline
\end{tabular}




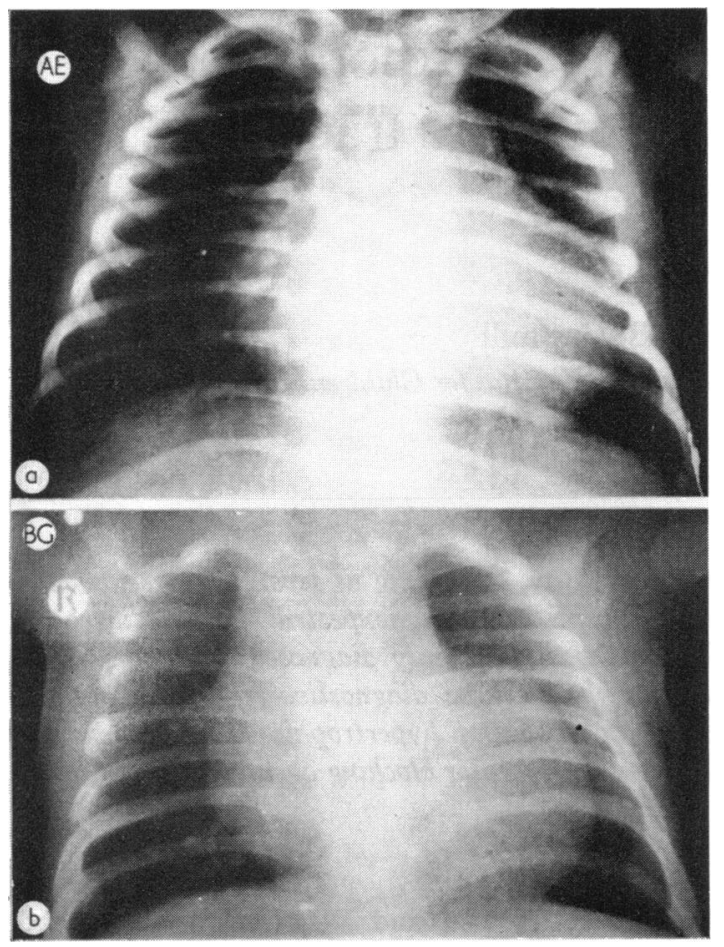

\section{Case I}

\section{Case reports}

A 3-day-old boy was referred for assessment of a cardiac murmur and possible cyanosis. The family history was not contributory. Physical examination revealed neither cyanosis nor congestive cardiac failure. The peripheral pulses were normal. The right and left ventricular praecordial impulses were abnormally prominent. An ejection systolic murmur, of grade $3 / 4$ intensity, was present at the second left intercostal space, and there was a mid-diastolic murmur, of grade $\mathrm{r} / 4$ intensity, at the lower left sternal border. The second heart sound was not definitely abnormal. The chest $x$-ray (Fig. ra) indicated moderate cardiomegaly, prominence of the main pulmonary artery, and normal pulmonary vascular markings.

The electrocardiogram (Fig. 2a) showed a mean frontal QRS axis of - I40 degrees, right atrial enlargement, and abnormal right ventricular preponderance. The clinical diagnosis was an endocardial cushion

FI I. I (a) The chest $\mathrm{x}$-ray in Case I showing moderate cardiomegaly, prominence of the main pulmonary artery segment, and normal pulmonary vascular markings. (b) The chest $\mathrm{x}-$ ray in Case 2 showing pronounced cardiomegaly and normal to slightly diminished pulmonary vascular markings.

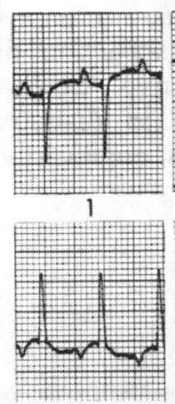

aVR

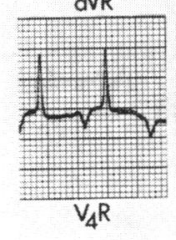

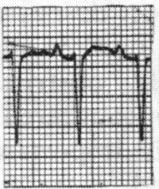

2

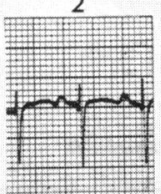

oVl

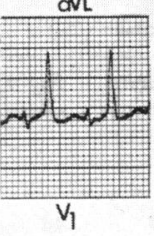

(a)

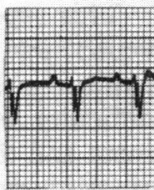

3

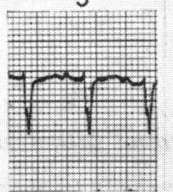

aVF

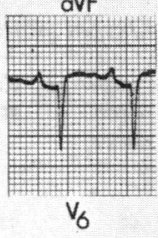

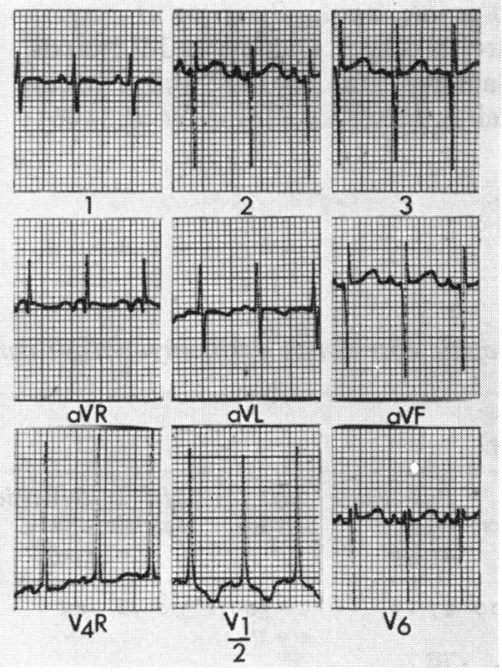

(b)

FIG. 2 The electrocardiogram in Case $I(a)$ and Case $2(b)$ both show extreme deviation of the mean frontal $Q R S$ axis, right atrial enlargement, and abnormal right ventricular preponderance. 

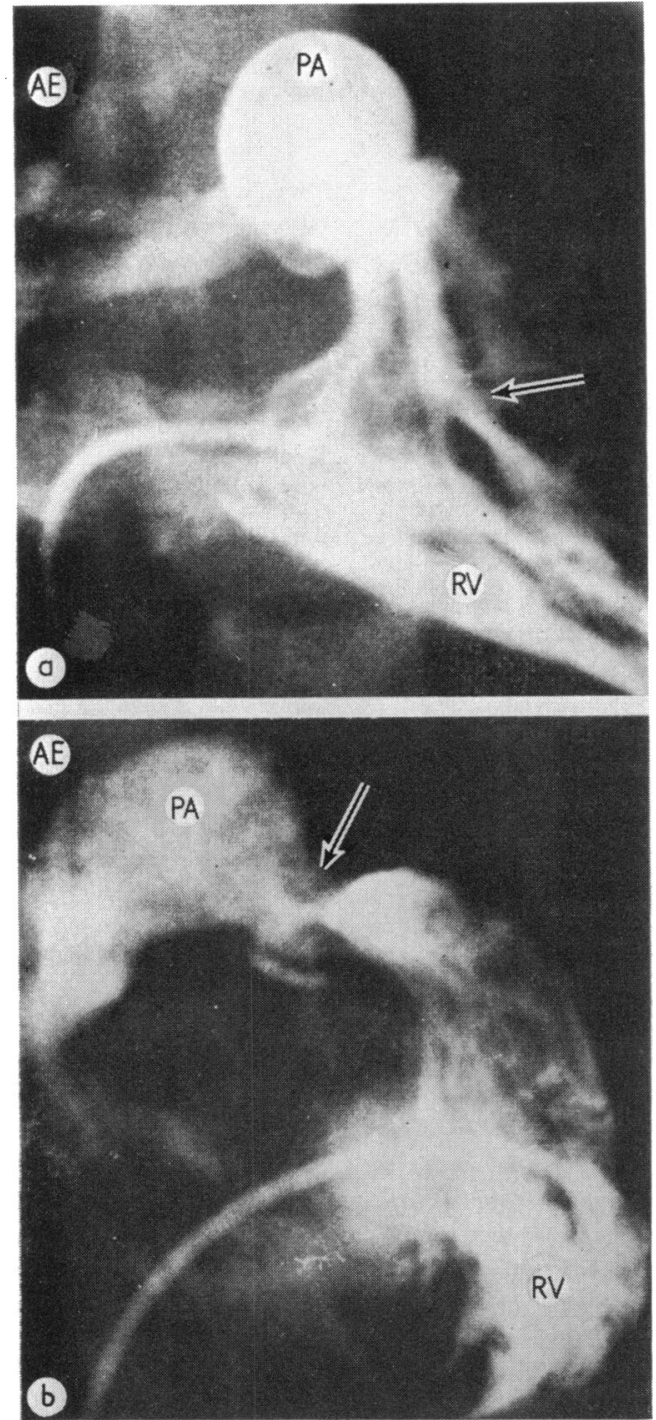

FIG. 3 Selective right ventricular angiocardiogram in Case I. $R V$, right ventricle; $P A$, pulmonary artery. On the frontal projection (a) the left margin of the right ventricle is diffusely indented (arrow) by the hypertrophied interventricular septum. The more discrete narrowing (arrow) at the level of the pulmonary valve and proximal main pulmonary artery segment can be seen in the lateral projection (b). There is pronounced trabeculation of the right ventricle, and the distal part of the main pulmonary artery is dilated.
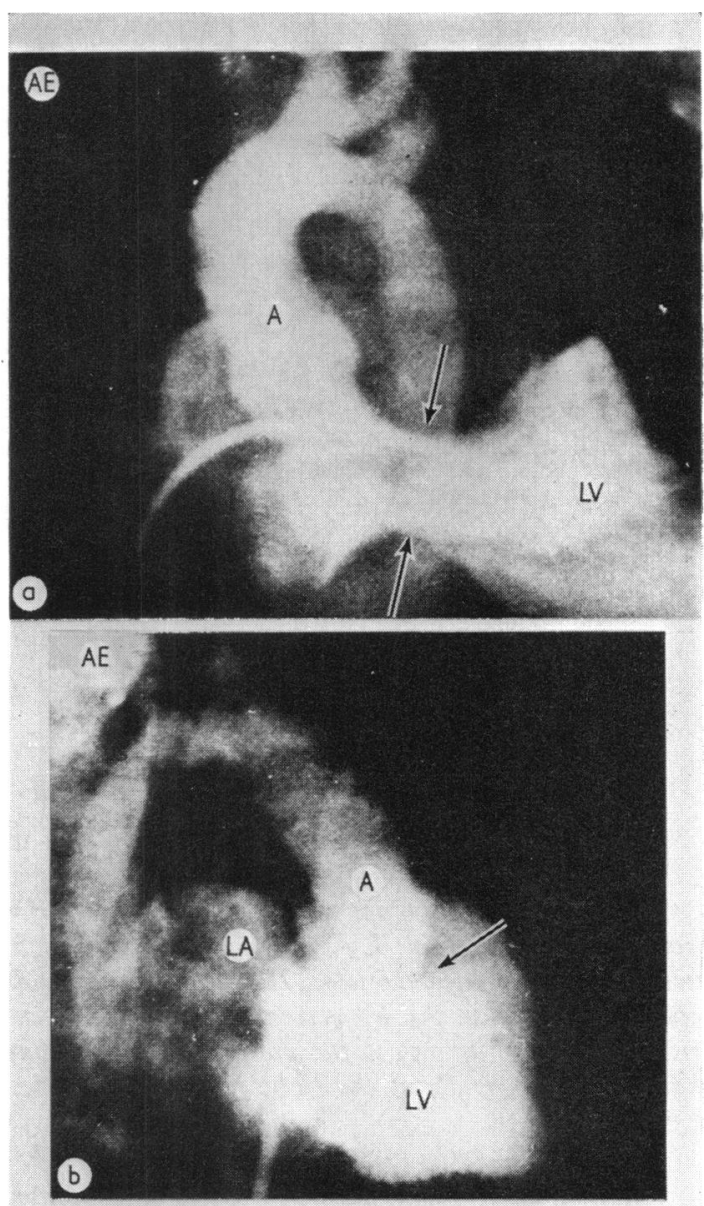

FIG. 4 Selective left ventricular angiocardiogram in Case $1 . L V$, left ventricle; $L A$, left atrium; $A$, aorta. The left ventricular outflow tract is narrowed (arrows) superiorly and inferiorly in the frontal projection (a) and anteriorly in the lateral projection (b) by the hypertrophied interventricular septum. There is some regurgitation of contrast material from the left ventricle to the left atrium.

defect, with possible pulmonary stenosis. He made poor progress with increasingly severe congestive cardiac failure despite digoxin and diuretic therapy. The results of cardiac catheterization at the age of 3 months are shown in the Table.

Selective right (Fig. 3a and b) and left (Fig. 4a and b) ventricular angiocardiograms were interpreted as showing severe biventricular outflow tract obstruction secondary to either an obstructive cardiomyopathy or a cardiac tumour, and pulmonary valve stenosis. His clini- 


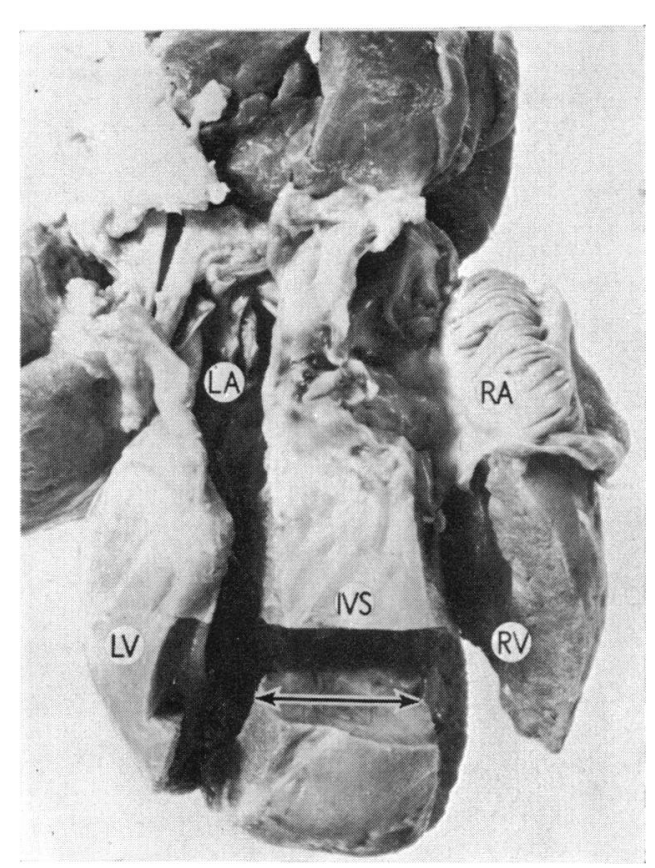

FIG. 5 The heart of Case I viewed from its posterior aspect. $L A$, left atrium; $L V$, left ventricle; $R A$, right atrium; $R V$, right ventricle; IVS, interventricular septum. Note that the hypertrophy of the interventricular septum (arrow) is far more pronounced than that of the free walls of the right and left ventricles.

cal condition deteriorated until, at the age of 6 months, surgical relief of the obstruction was attempted. Utilizing cardiopulmonary bypass, profound hypothermia, and complete circulatory arrest, an extensive resection of right ventricular muscle was performed; only partial relief of the obstruction was obtained. The close relation of the hypertrophied ventricular septum to the mitral valve apparatus prevented any attempt at relief of the left ventricular outflow obstruction. The patient did not survive operation.

At necropsy there was generalized cardiac hypertrophy (Fig. 5) with right and left ventricular free wall thickness of $0.7 \mathrm{~cm}$ and $1.0 \mathrm{~cm}$, respectively. The hypertrophy of the interventricular septum was disproportionately gross and had resulted in severe obstruction of both right (Fig. 6a) and left (Fig. 6b) ventricular outflow tracts. The free margins of both the mitral and tricuspid valve cusps showed nodular excrescences. The aortic and pulmonary valves, together with the remainder of the heart, were normal. Histological examination showed the individual ventricular muscle fibres to be variably enlarged and the muscle cell nuclei to be large, irregular, and hyperchromatic. Though more detailed examinations, by serial sections and electron microscopy, were not performed, the above gross and histopatho-

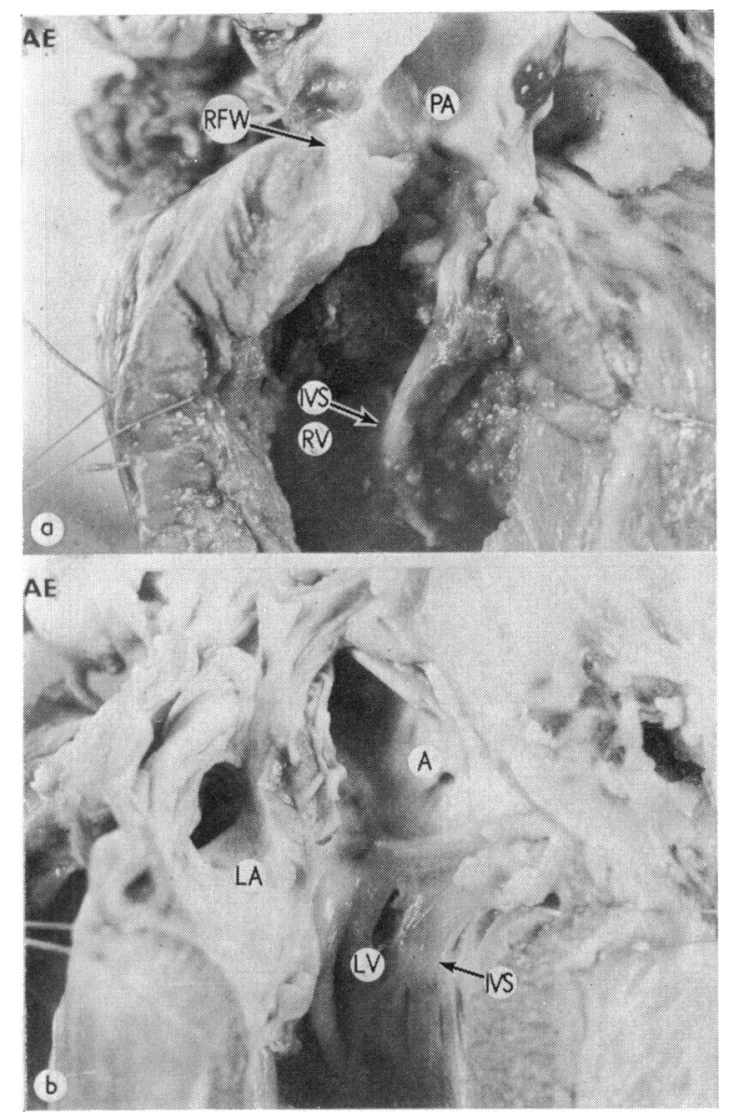

FIG. 6 The heart of Case I. The right ventricle is viewed from its anterior aspect (a) and the left ventricle from its posterior aspect (b). In (b) a part of the anterior wall of the left atrium and anterior cusp of the mitral valve have been removed to allow a better view of the left ventricular outflow tract. $A$, aorta; $L V$, left ventricle; $L A$, left atrium; $P A$, pulmonary artery; $R V$, right ventricle; $R F W$, right ventricular free wall; IVS, interventricular septum. The hypertrophied interventricular septum can be seen to obstruct both the right ( $a$, lower arrow) and left $(b, a r r o w)$ ventricular outflow tracts. Note the indentation at the level of the pulmonary valve produced by the hypertrophied free wall of the right ventricle ( $a$, upper arrow).

logical features are considered to be typical of idiopathic hypertrophic obstructive cardiomyopathy.

\section{Case 2}

This was a female infant in whom a cardiac murmur had been detected at birth. Apart from slow feeding she had made normal progress up to the time of referral at the 

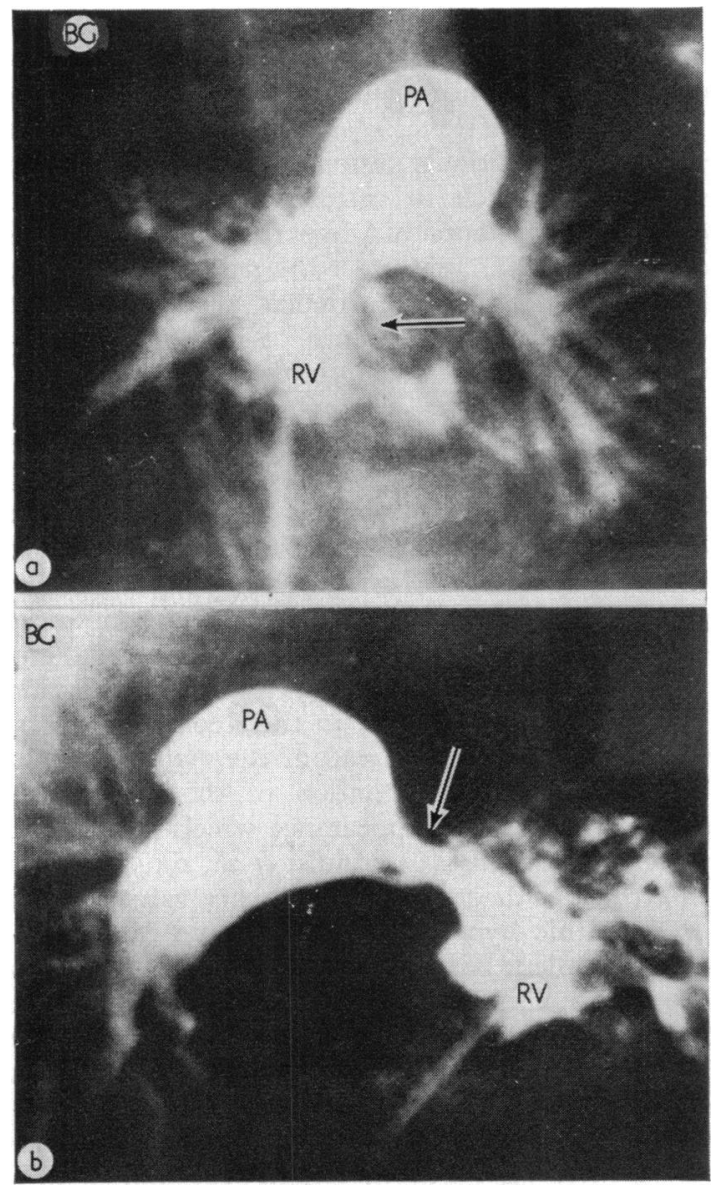

FIG. 7 Selective right ventricular angiocardiogram in Case 2. $P A$, pulmonary artery; $R V$, right ventricle. The frontal projection (a) shows the pronounced trabeculation of the right ventricle. The size of the right ventricular cavity is diminished, and this partially obscures the indentation (arrow) produced by the hypertrophied interventricular septum. The lateral projection (b) shows the discrete narrowing at the level of the pulmonary valve and proximal main pulmonary artery segment. The distal segment of the main pulmonary artery is dilated.

age of 7 weeks. As in the first case, the family history was not contributory. Physical examination revealed a wellnourished infant without cyanosis or signs of congestive cardiac failure. The peripheral pulses were normal. The right ventricular praecordial pulsation was prominent. An ejection systolic murmur, of grade 3/4 intensity, was present at the second left intercostal space. The chest $x$-ray (Fig. Ib) showed pronounced cardiomegaly with
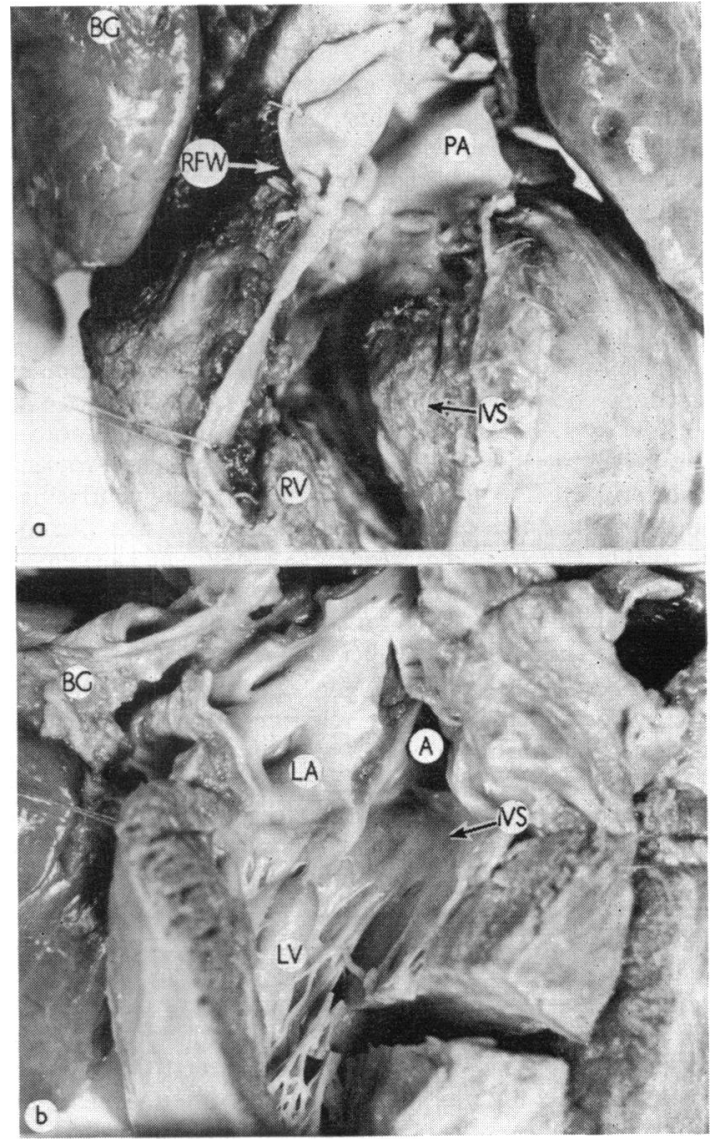

FIG. 8 The heart of Case 2. $A$, aorta; $L V$, left ventricle; $L A$, left atrium; $P A$, pulmonary artery; $R V$, right ventricle; $R F W$, right ventricular free wall; IVS, interventricular septum. The right ventricle is viewed from its anterior aspect $(a)$ and the left ventricle from its posterior aspect (b). In (b) a part of the anterior wall of the left atrium and anterior cusp of the mitral valve have been removed to allow a better view of the left ventricular outflow tract. The interventricular septum almost obliterates the right ventricular outflow tract ( $a$, black arrow) but does not appear to have caused any significant left ventricular outflow tract obstruction ( $b$, arrow). The site of the narrowing at the level of pulmonary valve, by the hypertrophied free wall of the right ventricle, is indicated ( $a$, white arrow).

normal to slightly diminished pulmonary vascular markings. The electrocardiogram (Fig. 2b) showed a mean frontal QRS axis of - II5 degrees, right atrial enlargement, and abnormal right ventricular preponderance. There was no change in her clinical state, and cardiac 
catheterization (Table) was performed at the age of Io weeks. A selective right ventricular angiocardiogram (Fig. $7 a$ and b) showed a heavily trabeculated right ventricle, and the pulmonary valve cusps were thought to be thickened and 'domed'. The clinical diagnosis of severe pulmonary valve stenosis was believed to have been confirmed. Four days after cardiac catheterization, an operation was performed. The technique used was the same as for the first case. The pulmonary valve, though opaque and deformed, was not stenosed. Instead, the right ventricular outflow obstruction was the result of pronounced hypertrophy of the interventricular septum. There was no obstruction to the left ventricular outflow as measured by pressure recordings at thoracotomy. Despite partial resection of the obstructing muscle mass and gusset reconstruction of the right ventricular outflow tract, the relief of the obstruction was incomplete. On the second postoperative day, she developed tachypnoea and was given digoxin. Thereafter she deteriorated progressively and died in low output cardiac failure on the fourth postoperative day.

At necropsy there was generalized cardiac hypertrophy, with right and left ventricular free wall thicknesses of 1.3 and $1.0 \mathrm{~cm}$, respectively. The hypertrophy of the interventricular septum was disproportionately severe, but, unlike the first case, the hypertrophy appeared to obstruct only the right ventricular outflow tract (Fig. 8a and b). The pulmonary valve cusps were thickened and deformed but there was no pulmonary valve stenosis. The aortic valve and remainder of the heart were normal. As in the first case, the histological examination was limited to light microscopy. There was gross generalized hypertrophy of the individual muscle fibres. There was no increase in interstitial fibrous tissue and no inflammatory cell infiltration. Since the typical histological appearance of idiopathic hypertrophic obstructive cardiomyopathy may be absent (Daoud et al., 1961; Paré et al., 196I), we believe that the gross pathological changes present in this case are due to idiopathic hypertrophic obstructive cardiomyopathy.

\section{Discussion}

Despite the alternative designation of idiopathic hypertrophic subaortic stenosis it has long been recognized that mild right ventricular obstruction may be present in idiopathic hypertrophic obstructive cardiomyopathy: in fact, it is not uncommon (Swan et al., 1971). However, the right ventricular obstruction may be both isolated and severe (Taylor, Bernstein, and Jose, 1964; Braunwald et al., 1964). Though severe right ventricular outflow obstruction in infancy due to idiopathic hypertrophic obstructive cardiomyopathy is rare, its recognition is important because of the therapeutic implications.

Even in retrospect the clinical features of our cases did not suggest the diagnosis of idiopathic hypertrophic obstructive cardiomyopathy. The QRS axis in the electrocardiograms is of interest since it was not present in the two similar cases previously reported. Though the angiocardiographic appearances led us to diagnose severe pulmonary valve stenosis, as the sole lesion in Case 2 and as an additional lesion in Case $I$, it is this appearance which in retrospect may have been diagnostic of idiopathic hypertrophic obstructive cardiomyopathy. In Case I the right (Fig. 3a) and left (Fig. 4a and $b$ ) ventricular angiocardiograms show the typical appearance of idiopathic hypertrophic obstructive cardiomyopathy due to encroachment upon the respective outflow tracts by the massively hypertrophied ventricular septum. However, the same appearance in Case 2 (Fig. 7a) is partially obscured by the generalized muscle hypertrophy which severely compromises the right ventricular cavity. Instead, the most striking abnormality, in both our cases, was the pronounced narrowing at the level of the pulmonary valve and proximal main pulmonary artery (Fig. $3 b$ and Fig. 7b) due, we believe, to their compression by the hypertrophied free wall of the right ventricle. It was the misinterpretation of this, previously unreported, atypical appearance which led us, and possibly Lundquist (Lundquist et al., 1965) to make an erroneous diagnosis of pulmonary valve stenosis in idiopathic hypertrophic obstructive cardiomyopathy. While it is at least conceivable that a similar appearance could result from the right ventricular hypertrophy secondary to long-standing severe pulmonary valve stenosis, we have not encountered such a case, and therefore believe that this angiocardiographic appearance should strongly suggest idiopathic hypertrophic obstructive cardiomyopathy.

The futility of attempted surgical relief of idiopathic hypertrophic obstructive cardiomyopathy in infancy is illustrated by our two cases. Beta-adrenergic receptor blocking drugs are the accepted initial treatment of choice, despite the fact that the mechanism whereby they exert their beneficial effect is controversial. The two proposed mechanisms, not necessarily mutually exclusive, whereby beta-adrenergic receptor blocking agents may improve the abnormal ventricular function in idiopathic hypertrophic obstructive cardiomyopathy are, first, a decrease in ventricular outflow obstruction (Flamm, Harrison, and Hancock, I968) and, second, an increase in ventricular compliance with consequent decrease in ventricular inflow restriction (Webb-Peploe, 1971). The negative inotropic effect of these drugs has been, at least, a relative contraindication to their use in the presence of cardiac failure, and this was the reason that propranolol was not used in our first case. However, the remarkable response to propranolol of Shand's case (Shand et al., 197I), despite con- 
gestive cardiac failure, suggests that beta-adrenergic receptor blockade may have been of benefit in our cases. Certainly digoxin, which by its positive inotropic effect is known to increase the severity of ventricular obstruction in idiopathic hypertrophic obstructive cardiomyopathy, may have been deleterious in both our cases.

We thank Dr. D. S. Stuckey for allowing us to report the second case.

\section{References}

Braunwald, E., Lambrew, C. T., Rockoff, S. D., Ross, J., Jr., and Morrow, A. G. (1964). Idiopathic hypertrophic subaortic stenosis, I, a description of the disease based upon an analysis of 64 patients. Circulation, 30, Suppl. 4, 3.

Cohen, J., Effat, H., Goodwin, J. F., Oakley, C. M., and Steiner, R. E. (1964). Hypertrophic obstructive cardiomyopathy. British Heart fournal, 26, 16.

Daoud, G., Gallaher, M. E., and Kaplan, S. (I96I). Muscular subaortic stenosis. American fournal of Cardiology, 7, 860.

Flamm, M. D., Harrison, D. C., and Hancock, E. W. (1968). Muscular subaortic stenosis. Circulation, 38, 846.

Lundquist, C. B., Amplatz, K., Palma, S. P., and Raghib, G. (1965). Angiographic findings in idiopathic myocardial hypertrophy with right and left ventricular outflow obstruction. American fournal of Roentgenology, 93, 315.

Moes, C. A. F., Peckham, G. B., and Keith, J. D. (1964). Idiopathic hypertrophy of the interventricular septum causing muscular subaortic stenosis in children. Radiology, 83, 283.

Neufeld, H. N., Ongley, P. A., and Edwards, J. E. (1960). Combined congenital suboartic stenosis and infundibular pulmonary stenosis. British Heart fournal, 22, 686.

Paré, J. A. P., Fraser, R. G., Pirozynski, W. J., Shanks, J. A., and Stubington, D. (196I). Hereditary cardiovascular dysplasia. American fournal of Medicine, 31, 37.

Rudhe, U., Zetterqvist, P., and Wallgren, G. (1966). Angiocardiography of hypertrophic obstructive cardiomyopathy in infancy and childhood. Annales de Radiologie, 9, 185.

Shand, D. G., Sell, C. G., and Oates, J. A. (1971). Hypertrophic obstructive cardiomyopathy in an infant-propranolol therapy for three years. New England fournal of Medicine, 285, 843.

Swan, D. A., Bell, B., Oakley, C. M., and Goodwin, J. (I97I). Analysis of symptomatic course and prognosis and treatment of hypertrophic obstructive cardiomyopathy. British Heart fournal, 33, 671.

Taylor, R. R., Bernstein, L., and Jose, A. D. (1964). Obstructive phenomena in ventricular hypertrophy. British Heart Fournal, 26, 193.

Teare, D. (1958). Asymmetrical hypertrophy of the heart in young adults. British Heart fournal, 20, I.

Webb-Peploe, M. (197I). Management of hypertrophic obstructive cardiomyopathy by beta-blockade. In Hypertrophic Obstructive Cardiomyopathy, Ciba Foundation Study Group No. 37, p. I03. Ed. by G. E. W. Wolstenholme and M. O'Connor. Churchill, London.

Requests for reprints to Dr. P. A. Barr, Adolph Basser Institute of Cardiology, Royal Alexandra Hospital for Children. Camperdown 2050, Sydney, Australia. 